\title{
A Review of a Few Key Factors Regulating Voluntary Feed Intake in Ruminants ${ }^{1}$
}

\author{
Dwight S. Fisher*
}

\begin{abstract}
During the history of ruminant nutrition many factors have been proposed as regulators of voluntary feed intake. In some cases, the implicit assumption has been that a factor acted independently and exclusively of other mechanisms. A knowledge of ruminant digestive anatomy aids in understanding both the ecological niche and the feeding behavior of the ruminant animal. Factors controlling ruminant intake should be assumed to function with multiple interactions. A number of feedback regulators such as distension, protein, and energy should be considered in the context of their interacting regulatory effects when attempting to predict intake. Behavioral aspects also influence voluntary feed intake through associations formed via postingestive feedback. Ruminants can learn to identify particular feeds and alter intake on the basis of past experiences. An integrated approach is proposed as a means of understanding ruminant feed intake regulation and eventually to improving prediction of intake. Empirical mathematical methods are likely to be fundamental to developing understanding and models of feed intake because of the difficulty of studying the central nervous system. In spite of these difficulties, knowledge of theoretical feedbacks has already been used to develop practical ruminant feeding strategies.
\end{abstract}

$\mathrm{F}$ OR AS LONG as mankind has kept ruminant livestock there has probably been interest in their digestive tract and their ability to thrive on herbaceous material. This interest naturally leads to speculation on management strategies designed to improve ruminant performance and more efficiently meet human needs (Van Soest, 1994). Present day ruminant production systems have stimulated research to improve the prediction of feed intake to increase the efficiency of management systems (Tedeschi et al., 2000). Researchers have identified many factors that are correlated with intake and have proposed many of these factors as regulators of intake. One key feature of a regulatory feedback is the discovery and description of a physical feedback mechanism. Even when this difficult process is accomplished, the task remains of understanding and describ-

${ }^{1}$ USDA prohibits discrimination in all its programs and activities on the basis of race, color, national origin, gender, religion, age, disability, political beliefs, sexual orientation, and marital or family status (not all prohibited bases apply to all programs). Persons with disabilities who require alternative means for communication of program information (Braille, large print, audiotape, etc.) should contact USDA's TARGET Center at (202) 720-2600 (voice and TDD). To file a complaint of discrimination write USDA, Director, Office of Civil Rights, Room 326-W, Whitten Building, 14th and Independence Avenue, SW, Washington, DC 20250-9410 or call (202) 720-5964 (voice or TDD). USDA is an equal opportunity provider and employer. Use of trade names in this publication does not imply endorsement by USDA, ARS of the products named or criticism of similar ones not mentioned.

USDA-ARS, 1420 Experiment Station Road, Watkinsville, GA, 30677-2373. Received 29 May 2001. *Corresponding author (dsfisher@arches.uga.edu).

Published in Crop Sci. 42:1651-1655 (2002). ing the integration of multiple feedback signals in the control of feeding behavior (Forbes, 1995, 1996). Because of the experimental difficulties in the study of the central nervous system, the use of empirical mathematical methods are likely to remain critical to synthesizing the current understanding of intake regulation (Fisher, 1996).

This brief review will cover some key aspects of ruminant anatomy, physical and metabolic feedback mechanisms, and some practical applications of theoretical feedbacks in the context of impacts on voluntary feed intake and feeding systems.

\section{ANATOMY}

In the investigation of voluntary feed intake in ruminants, it is instructive to consider the anatomy of domestic ruminants in relation to the anatomy of all ruminants and the ecological niches occupied by ruminants in the wild. This should seem obvious but ruminant anatomy is not generally considered a key to understanding forage utilization. For example, the two-volume textbook Forages (Barnes et al., 1995) in its 5th edition has 60 chapters and 91 authors but it has no chapter on herbivore anatomy. This is not to say anatomy should be regarded as trivial; however, anatomy is obviously not generally perceived as fundamental to understanding forage utilization. This is true of herbivores in general and ruminants in particular although there are general comments on the anatomy of herbivores in the textbook (Ely, 1995; Evans, 1995; Fisher et al., 1995).

Domestic ruminants have been selected and maintained by humans for thousands of years but the niche occupied by the wild ancestors of domestic ruminants has a direct bearing on the digestive anatomy present today and utilized in modern production systems. An animal may be fed a diet that is very different from the diet that characterizes the ecological niche of the ruminant's adaptation. With appropriate management, animal performance may be excellent on a diet that is more characteristic of a monogastric animal. However, human management of domestic ruminants interacts with the natural limitations and specializations still present in domestic ruminants.

There are approximately 180 species of ruminants existing in the world today. The digestive tracts of ruminants are well known to contain multiple stomachs and the term rumination is used in modern English to indicate the process of chewing the cud as well as to meditate or turn something over in the mind. However, ruminant digestive tracts are not uniform. On the contrary, they are highly specialized to process specific diets (Hofmann, 1988, 1998). The ruminant's digestive tract is fit to a particular ecological niche and ruminants range in specialization from concentrate selectors through intermediate feeders to species adapted to grazing. A gener- 


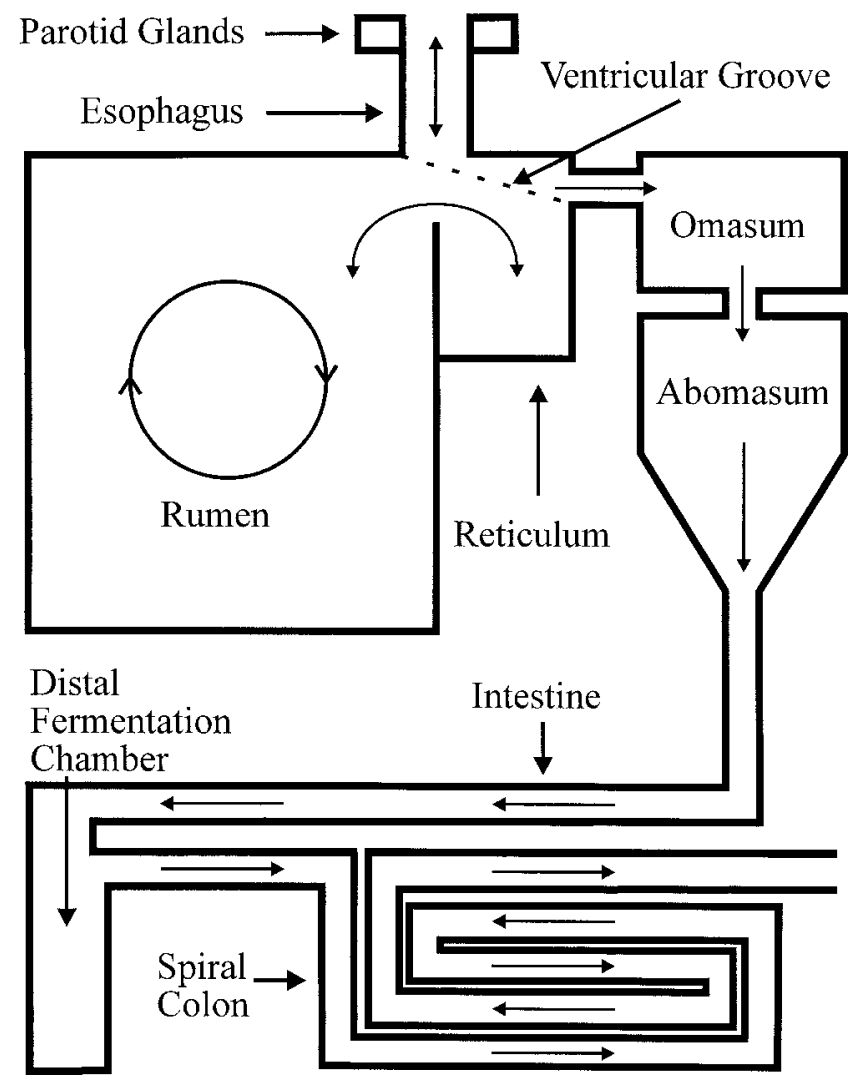

Fig. 1. A diagrammatic representation of the key aspects of the ruminant digestive system. The relative size of the parotid glands, rumen, distal fermentation chamber, and spiral colon are varied to fit a ruminant to a particular ecological niche.

alized diagram of the ruminant digestive tract (Fig. 1) illustrates some of the anatomical features that vary to fit a ruminant to a particular ecological niche with a specific type of herbaceous diet and digestive strategy.

Ruminants that are concentrate selectors have relatively large parotid glands and small rumens with higher rates of passage, larger distal fermentation chambers, and larger spiral colons in comparison to grazing ruminants (Hofmann, 1998). The parotid glands of concentrate selectors are sometimes specialized to secrete compounds that make it possible to consume higher concentrations of plant secondary compounds. For example, browse with high levels of tannins may be readily consumed by a concentrate selector but avoided by a grazing ruminant. The concentrate selector has a relatively larger emphasis on hindgut fermentation and decreased emphasis on ruminal fermentation compared with a grazing ruminant. Hindgut fermentation following hydrochloric acid exposure in the abomasum facilitates hemicellulose digestion. This process is relatively more important in the concentrate selector than in the grazing ruminant. Although the ventricular groove is apparently functional in all ruminants it may be especially useful in the concentrate selector for a partial bypass of liquids when consuming succulent forage material. Bypassed liquid may carry highly digestible materials such as simple sugars and soluble starch directly to the omasum and on to abomasum for digestion with- out the typically extensive degradation by rumen microbes (Hofmann, 1998). It is unlikely that this anatomical feature would be so well developed in the adult animal if it were not functional.

Grazing ruminants have proportionally smaller parotid glands that produce salivary buffers for their relatively large rumens with lower rates of passage (Hofmann, 1998). The smaller parotid glands would indicate a dietary specialization to grasses and forbs with few concentrated secondary compounds. Since grazing ruminants have a relatively slow rate of passage with an increased emphasis on ruminal fermentation, they also have relatively small distal fermentation chambers and spiral colons. Overall, grazing ruminants are specialized for efficient foregut fermentation with a lower rate of passage. They are specialized for a diet of digestible cellulose and are not well suited to consuming large amounts of relatively indigestible fiber, plant materials with concentrated secondary compounds, or diets very low in fiber.

Cattle (Bos taurus and Bos indicus) and sheep (Ovis aries) have anatomical characteristics that identify them as grazing ruminants while goats (Capra hircus hircus) have characteristics that identify them as intermediate between concentrate and grazing ruminants (Hofmann, 1988). The digestive tracts of domesticated ruminants are specialized as efficient processors of feeds with large amounts of digestible cellulose. Efficiency of digestion is elevated with foregut fermentation but the daily intake of digestible nutrients may be reduced on poor quality feeds because of the relatively slow rate of passage from the rumen even if the diet is otherwise nutritionally balanced. In other words, the grazing ruminant efficiently utilizes cellulosic material by fermentation in the rumen but this does not necessarily result in a high intake of nutrients (Van Soest, 1994). In addition to reduced intake due to a full rumen, another disadvantage to this strategy is the reduction in feed value as a large portion of the soluble carbohydrate, starch, and protein is fermented in the rumen by microbes before absorption in the hindgut. The ventricular groove is only partially effective as a rumen bypass mechanism with very succulent diets, or perhaps during deglutition associated with rumination, but is relatively less useful on highly fibrous diets.

The ecological niche occupied by grazing ruminants requires the processing of large amounts of fibrous feeds. Sensing and maintaining rumen fill is an important trait for occupying that niche. The reticulo-rumen serves as a fermentation chamber and the maintenance of the reticulo-rumen and its complex of microorganisms is critical to the survival of the animal. Sensitivity to postingestive feedback and the ability to select feeds with positive postingestive consequences and avoid feeds with negative postingestive consequences should be a highly developed trait.

For better or worse, the principal ruminants selected for domestication by mankind are grazing ruminants and feed intake phenomena should be consistent with their natural adaptation. The grazing ruminant occupies a feeding niche that has made it especially valuable to 
civilization. Some modern feeding systems provide diets that are quite different from the ruminant's dietary niche but in the search for management strategies that may result in greater performance, it is critical to recognize interactions with an anatomy formed before domestication. This anatomy is tailored for efficiency in the utilization of a relatively digestible cellulose diet.

\section{FEEDBACK MECHANISMS \\ Distension or Fill Feedback}

Distension or fill is an intuitive feedback but it isn't without some controversy (Allen, 1996; Forbes, 1995, 1996). Tension receptors are present in ruminant animals and Allen (1996) does an excellent job of presenting the many experimental tests of distension feedback (Fig. 2). The evidence for this feedback is so widespread that even when it is rejected as being important in longterm control of intake it is proposed as controlling behavior during meals (Ketelaars and Tolkamp, 1996). However, even if the study is limited to variation in intake rate during a meal, Fisher and Baumont (1994) showed that distension alone did not explain the observed variation. They showed that distension feedback could be mathematically integrated with chemostatic or energy feedback to explain variation in intake rates during meals. Allen (1996) and Forbes (1996) point out there are some experiments that found no reduction to intake with increased distension and others that suffer from the criticism that distension took place to a degree that is not physiological and therefore wouldn't be involved in normal regulation of intake. It appears that the rumen should be viewed as having "reserve capacity" with some animal classes and conditions fed some diets and therefore an experimenter would not be likely to depress intake in all diets by adding inert fill (Dado and Allen, 1995). This explanation is consistent with the observation that grinding feedstuffs to increase the rate of passage and therefore increase feed intake is more effective with poor quality diets than with higher quality diets (Minson, 1963). Distension should not be considered separately from other possible feedbacks when predicting the impact on feed intake.

\section{Chemostatic or Metabolic Feedback}

If the rumen has a reserve capacity on some feeds of moderate to high nutritive value then some other factor or factors related to the metabolism of the feed must be limiting intake (Fig. 2). These regulatory factors are known as chemostatic or metabolic feedbacks (Illius and Jessop, 1996). The ruminant has a demand for energy and other dietary components such as protein that it attempts to meet by consuming available feeds. In addition, animals tend to achieve and maintain a particular percent body fat. This metabolic control is referred to as a lipostatic feedback. Recent work has demonstrated the importance of interacting levels of leptin and insulin in control of the lipostatic set point (Ceddia et al., 2001).

The demand for feed in a healthy animal is related
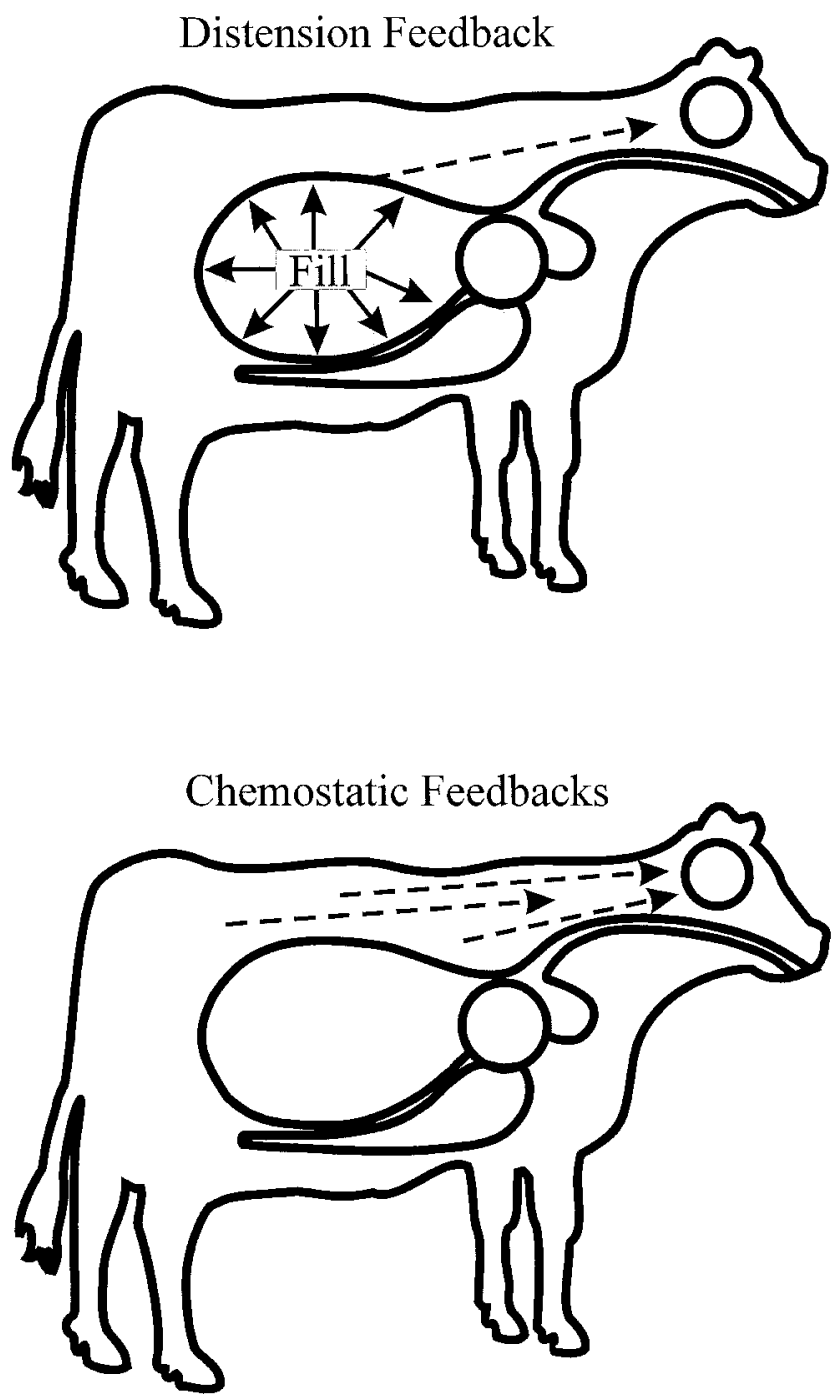

Fig. 2. Contrast of distension or fill feedback with chemostatic feedback in regulating intake. The ruminant central nervous system integrates multiple feedbacks to regulate feed intake.

to the animal's ability to metabolize feed and that varies widely with animal class and condition (Illius and Jessop, 1996). Dietary imbalances can increase feed intake in an attempt to compensate for a deficient nutrient while disposing of surplus nutrients. For example, balance is especially important with regard to energy and protein intake as the animal physiologically integrates multiple nutritional signals. If the dietary imbalance is large then intake may be reduced (Illius and Jessop, 1996; Fisher, 1996). When protein is limited, then voluntary dry matter intake of highly digestible (high energy) diets may decrease dramatically because of metabolic limitations to processing energy. Constraints to intake are serious when protein is limiting but when diets are very high in protein, then protein may simply be metabolized for energy. Although distension and chemostatic effects are often viewed separately for convenience (Fig. 2 ), the ruminant central nervous system integrates the signals. 


\section{Oxygen Efficiency Theory}

It has also been proposed that intake is simply regulated to maximize the efficiency of oxygen consumption (Ketelaars and Tolkamp, 1996). It is hypothesized that the costs and benefits of feed intake are considered and feed intake is regulated to maximize the yield of net energy per liter of oxygen consumed. Rumen fill is viewed as a consequence of animal feeding behavior rather than having a regulatory effect on intake. This argument is partially based on aging theory and the demonstrated relationship of oxidative damage to aging. The authors extend the results of the aging work and suggest that, "animals try to achieve an optimal balance between the benefits and costs of feeding behavior." This statement is not consistent with observed feeding behavior. In mammals, it is relatively simple to extend lifespan with a moderately restricted caloric intake (Rogina et al., 2000). In practice, ad libitum intake of food limits the utility of the effect. Given ad libitum access to feed, animals overeat and shorten their lifespan. Building on older work that demonstrated substantially increased lifespan with nutrient dense but caloric deficient diets, recent work with fruit flies (Drosophila melanogaster) has shown that life span can be greatly increased by a single gene mutation that reduces cellular uptake of energy even though feed intake and vigor remain normal (Rogina et al., 2000). The single gene mutation seems to act on a cellular level to reproduce the effects of caloric restriction. The literature and recent work in molecular biology clearly show that animals shorten their lifespan by over consuming feeds and do not optimize the benefits and costs of feed intake.

Ketelaars and Tolkamp (1996) state that since scientists are, "Trained to view animals as producers of milk and meat, we find it difficult to imagine that animals have their own objectives that are possibly quite different from rapid growth and high milk production." Of course intake is closely linked to metabolism and metabolism is linked to oxygen consumption (Jones, 1998). In addition, while it is true that selection pressure for rapid growth and milk production increased as ruminants were domesticated, it is also true that ruminants were attractive to humans because of their rapid growth and milk production before domestication. Reproductive fitness in either wild or domesticated ruminants is affected by longevity but it is not a trait required for reproduction. The rigors of reproductive behavior and avoiding predation in wild ruminants and (for recent history) the impact of the abattoir on domestic ruminants place a premium on rapid growth and early sexual maturity rather than longevity. It is clear that oxygen consumption is tightly regulated and associated with processing consumed feeds. However, the idea that animals "try to balance the benefits and costs of feeding behavior" is not consistent with the factors that result in their reproductive success or the observations of energy consumption in excess of requirements.

\section{APPLICATIONS OF THEORIES}

A useful theory is predictive and yields testable hypotheses. If a particular feedback mechanism exists, then it should suggest management practices that may increase animal performance although interaction with other feedbacks may limit the utility. For example, distension feedback suggests that processing forage to speed its flow through the rumen should increase intake and should be most effective with forages of lower quality and slowest rates of passage from the rumen. Minson reviewed the evidence for this effect many years ago (Minson, 1963).

Making use of metabolic feedbacks in feeding systems is more complex. With forage diets of moderate energy content, feed intake should increase with an increase in diet digestibility as a result of increased digestion and passage. If metabolic feedbacks exist, the addition of inert bulk to the rumen should reduce intake but may be partially compensated for by a higher tolerated level of fill. Both of these effects have been observed in published studies (Allen, 1996). Given the ecological niche of the ruminant, selection pressure should have resulted in an animal that is very sensitive to the energy content of forage. With diets of moderate digestibility, selection pressure should have favored ruminants that prefer forages with higher energy content and are able to select them when offered a choice. This effect has been demonstrated recently (Fisher et al., 1999). Experimental results also indicate that ruminants express an integrated response to protein:energy ratio and the ruminant response to protein and energy must be considered in the context of the requirements of the suite of rumen microorganisms and the whole animal (Illius and Jessop, 1996; Tedeschi et al., 2000). Both the animal and the suite of rumen microbes active in degrading plant cell walls have a protein requirement that should be considered when supplementing diets low in protein.

Feedbacks have postingestive consequences that have been shown to be effective in modifying feed intake (Early and Provenza, 1998; Provenza 1995). As pointed out by Illius and Jessop (1996), "it is worth noting that the probable reason that voluntary intake is so difficult to predict from first principles is that it is, ultimately, a psychological phenomenon." The knowledge that psychological constraints are present may also be useful in some production settings. For example, Baumont et al. (1990) showed that providing additional fresh forage at the end of a meal could be used to stimulate additional intake. In this case, preference for a feed is used to overcome satiation and precipitate an additional meal. Some shepherds make use of a similar effect (Baumont et al., 2000) by leading sheep to pastures with high availability and moderate palatability for the main meal of the day but saving the most highly preferred feeds for late in the day. Shepherds observe the sheep carefully as they feed and, when the sheep appear to be reaching satiation, the shepherds move the sheep to a pasture species that is highly preferred by the sheep to stimulate feeding late in the day. This takes advantage of the sheep's preference for a particular feed as well as the higher digestibility of forage toward the end of the day as a result of photosynthesis and starch accumulation. 


\section{SUMMARY}

Existing theories of intake regulation offer many testable hypotheses that have been the subject of many fruitful experiments. However, the integration of the multiple feedback signals is a complex psychological phenomenon that may be modeled empirically as work proceeds to uncover the underlying mechanisms. This becomes an iterative process of predicting and learning by deviations from predictions. The interaction of distension feedback with multiple chemostatic feedbacks has been a profitable field of research. In the future, novel mathematical and experimental approaches will be needed to consider each feedback signal properly in light of the other feedbacks.

\section{REFERENCES}

Allen, M.S. 1996. Physical constraints on voluntary intake of forages by ruminants. J. Anim. Sci. 74:3063-3075.

Barnes, R.F, D.A. Miller, and C.J. Nelson. 1995a. Forages, volume I: An introduction to grassland agriculture. 5th ed. Iowa State Univ. Press, Ames.

Barnes, R.F, D.A. Miller, and C.J. Nelson. 1995b. Forages, volume II: The science of grassland agriculture. 5th ed. Iowa State Univ. Press, Ames.

Baumont, R., S. Prache, M. Meuret, and P. Morand-Fehr. 2000. How forage characteristics influence behaviour and intake in small ruminants: a review. Livestock Prod. Sci. 64:15-28.

Baumont, R., N. Seguier, and J.P. Dulphy. 1990. Rumen fill, forage palatability, and alimentary behavior in sheep. J. Agric. Sci. (Cambridge) 115:277-284

Ceddia, R.B., W.N. William, Jr., and R. Curi. 2001. The response of skeletal muscle to leptin. Frontiers in Bioscience 6:90-97.

Dado, R.G., and M.S. Allen. 1995. Intake limitations, feeding behavior, and rumen function of cows challenged with rumen fill from dietary bulk or inert bulk. J. Dairy Sci. 78:118-125.

Early, D.M., and F.D. Provenza. 1998. Food flavor and nutritional characteristics alter dynamics of food preference in lambs. J. Anim. Sci. 76:728-734.

Ely, D.G. 1995. Forage for sheep, goats, and rabbits. p. 313-326. In R.F Barnes et al. (ed.) Forages, volume II: The science of grassland agriculture. 5th ed. Iowa State Univ. Press, Ames.

Evans, J.L., 1995. Forages for horses. p. 303-312. In R.F Barnes et al. (ed.) Forages, volume II: The science of grassland agriculture 5 th ed. Iowa State Univ. Press, Ames.

Fisher, D.S. 1996. Modeling ruminant feed intake with protein, chemostatic, and distension feedbacks. J. Anim. Sci. 74:3076-3081.

Fisher, D.S., J.C. Burns, and J.E. Moore. 1995. The nutritive evaluation of forage. p. 105-115. In R.F Barnes et al. (ed.) Forages, volume I: An introduction to grassland agriculture. 5th ed. Iowa State Univ. Press, Ames.

Fisher, D.S. and R. Baumont. 1994. Modeling the rate and quantity of forage intake by ruminants during meals. Agric. Syst. 45:43-53.

Fisher, D.S., H.F. Mayland, and J.C. Burns. 1999. Variation in ruminant preference for tall fescue hays cut at either sundown or sunup. J. Anim. Sci. 77:762-768.

Forbes, J.M. 1995. Voluntary Food Intake and Diet Selection in Farm Animals. CAB Int., Oxon, UK.

Forbes, J.M. 1996. Integration of regulatory signals controlling forage intake in ruminants. J. Anim. Sci. 74:3029-3035.

Hofmann, R.R. 1988. Morphophysiological evolutionary adaptations of the ruminant digestive system. p. 1-20. In: A. Dobson and M.J. Dobson (ed.) Aspects of digestive physiology in ruminants. Comstock Publishing Assoc., Ithaca, NY.

Hofmann, R.R. 1998. How ruminants adapt and optimize their digestive system "blueprint" in response to resource shifts. p 220-229. In E.R. Weibel et al. (ed.) Principles of animal design: The optimization and symmorphosis debate. Cambridge Univ. Press, New York.

Illius, A.W., and N.S. Jessop. 1996. Metabolic constraints on voluntary intake in ruminants. J. Anim. Sci. 74:3052-3062.

Jones, J.H. 1998. Symmorphosis and the mammalian respiratory system: what is optimal design and does it exist? p. 241-248. In E.R. Weibel et al. (ed.) Principles of animal design: The optimization and symmorphosis debate. Cambridge Univ. Press, New York.

Ketelaars, J.J.M.H. and B.J. Tolkamp. 1996. Oxygen efficiency and the control of energy flow in animals and humans. J. Anim. Sci. 74:3036-3051.

Minson, D.J. 1963. The effect of pelleting and wafering on the feeding value of roughage - A review. J. Br. Grassl. Soc. 18:39-50.

Provenza, F.D. 1995. Postingestional feedback as an elementary determinant of food preference and inake in rumiants. J. Range Manage. 48:2-17.

Rogina, B., R.A. Reenan, S.P. Nilsen, and S.L. Helfand. 2000. Extended life-span conferred by cotransporter gene mutations in Drosophila. Science 290:2137-2140.

Tedeschi, L.O., D.G. Fox, and J.B. Russell. 2000. Accounting for the effects of a ruminal nitrogen deficiency within the structure of the Cornell Net Carbohydrate and Protein System. J. Anim. Sci. 78: $1648-1658$.

Van Soest, P.J. 1994. Nutritional ecology of the ruminant. Cornell Univ. Press, Ithaca, NY 